\title{
RELEVANSI PERDEBATAN LIBERALISME VERSUS KOMUNITARISME UNTUK KONTEKS INDONESIA ${ }^{1}$
}

\author{
Otto Gusti Madung \\ Seminari Tinggi Ledalero Maumere Flores \\ Email: ottomadung@hotmail.com
}

\section{Abstract}

The crisis of solidarity on the one band and political identity that denies the diversity on the other band is a big problem that plagued the nation's center of Indonesia. This issue is trying to read in a pbilosophical discourse about the glass gye komunitarisme versus liberalism. The debate between these two philosopbies can be drawn mazhap its relevance to the context of Indonesia. Here Pancasila occupies a special position.

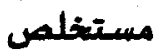

أزمة التضامن على الهوية من جهة، والسياسية التي تنفي التنوع من ناحية أخرى مشكلة كيرة

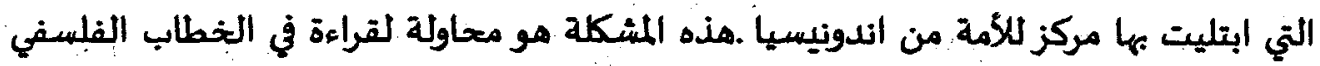
حول الزجاج العين مقابل الليبرالية .ويمكن امتخلاص النقاش بين هذه الملفارس ائنين من فلسفة ذات الصلة في سياق انلونيسيا .هنا البانشاسيلا تحتل مكانة خاضية.

Keywords: Komunitarisme, Islam, Liberalisme, Indonesia, Budaya

1 Tulisan ini merupakan perluasan dari makalah penulis pada acara bedah buku 'Politik Diferensiasi versus Politik Martabat Manusia?" yang diselenggarakan oleh Pusat Studi Islam-. Universitas Islam Indonesia, Yogyakarta pada tanggal 6 Februari 2012 


\section{A. Pendahuluan}

Beberapa waktu terakhir media massa menyuguhkan kepada publik berita seputar kekerasan aparat keamanan terhadap warga negara yang seharusnya mendapat perlindungan dari negara. Insiden terakhir terjadi di Sape, Bima pada tanggal 24 Desember 2011 di mana aparat polisi menembak mati 3 warga sipil yakni Arief Rahman (19), Syaiful (17) dan Ansyari (20). Menurut laporan Indonesian Police Watch (IPW) sepanjang tahun 2011 kebrutalan polisi telah menewaskan16 warga sipil dan menyebabkan 69 orang menderita luka. Laporan IPW ini merujuk pada tiga kejadian yakni insiden di Mesuji, Papua dan Sape. Tentu jumlah korban akibat brutalitas aparat keamanan jauh lebih besar dari angka tersebut di atas, sebab cukup banyak insiden yang tidak terekam publik.

Di balik ketiga insiden berdarah di atas terdapat konflik sumber daya alam antara warga masyarakat lokal dengan perusahan atau korporasi. Di Sape pemicu kekerasan adalah ketegangan antara masyarakat lokal dan korporasi pertambangan, di Mesuji antara masyarakat dan perusahan kelapa sawit dan di Papua terdafat konflik berkepenjangan antara masyarakat lokal yang terpinggirkan dan mengalami pemiskinan di tengah gelimang kemewahan dan profit yang diraub perusahan Freeport. ${ }^{2}$

Anehnya pada hampir semua konflik tersebut negara atau aparat keamanan berdiri kokoh sebagai pembela korporasi. Secara lugas dapat dikakatan, negara menampilkan diri sebagai anjing penjaga malam korporasi-korporasi dari serangan masyarakat lokal. Pertanyaan, untuk apa kita masih bernegara jika negara tidak lebih dari perpanjangan tangan korporasi-korporasi multinasional? Apakah frase nasionalisme masih punya makna ketika negara tampil sebagai Leviatban atau raksasa yang siap memangsa anak kandungnya sendiri? Apakah patriotisme masih punya tempat di tengah krisis kehidupan bernegara?

Ketidakpedualian negara thadap kehidupan mayoritas warga negara dibenarkan secara empiris oleh sejumlah data ketidakadilan sosial. Beberapa waktu lalu harian Kompas menurunkan sejumlah data berikut. Menurut catatan

2 Data diambil dari pernyataan sikap anggota masyarakat sipil di Naumere, Flores, NTT ketia mengadakan aksi ke Polres Sikka, Maumere, NTT sebagai ungkapan solidaritas terhadap korban kekerasan negara di Sape, Bima. 
Kompas, aset 300 orang terkaya di Indonesia sama dengan 60 prosen APBN, aset 40 orang terkaya setara dengan kekayaan 60 juta penduduk termiskin dan 80 persen sumber daya alam kita dikuasai oleh pihak asing. ${ }^{3}$

Data-data ini membuktikan bahwa sebagai bangsa kita gagal membangun sebuah dunia atau rumah bersama. Dunia bersama mengandaikan adanya pengalaman bersama. Namun bagaimana pengalaman bersama itu dapat direproduksi jika ketidakadilan sosial menganga leber, jika segelintir orang menghambur-hamburkan uang negara, sementara mayoritas warga tercecer secara politis, sosial dan ekonomi?

Krisis nasionalisme yang tengah dialami bangsa Indonesia menuntut negara dan masyarakat sipil untuk membangun kembali rumah bersama bernama Indonesia. Rumah bersama tersebut harus dibangun di atas dua pilar utama yakni keadilan dan solidaritas. Dalam tulisan ini saya coba menempatkan diskusi seputar pencarian pilar dasar bangunan negara moderen Indonesia dalam kerangka diskursus filsafat politik kontemporer: Komunitarisme versus Liberalisme. Diskursus ini sesungguhnya tidak baru dalam sejarah ketatanegaraan Indonesia. Pada saat berdirinya republik ini diskusi dengan nuansa yang sama muncul ketika terjadi perdebatan antara Soepomo dengan konsep negara integralistiknya dan Muhamad Hatta yang memperjuangkan agat hak-hak individual dimasukkan ke dalam UUD 45.

\section{B. Komunitarisme versus Liberalisme}

Komunitarisme adalah sebuah mazhab filsafat yang dicetuskan oleh sekelompok pemikir anglosaxon yang mengkritisi konsep kontrak sosial seperti dikembangkan John Rawls dan liberalisme pada umumnya. Perdebatan liberalisme versus komunitarisme dimulai awal tahun 80-an dan berkembang begitu cepat. Komunitarisme terdiri dari macam-macam posisi berbeda, namun mereka sepakat pada beberapa hal mendasar. kaum komunitarian menggarisbawahi kekurangan filsafat sosial yang berorientasi pada liberalisme moderen serta pentingnya tuntunan etis dan pandangan hidup bersama. Secara filosofis kaum komunitarian merujuk pada Aristoteles, Thomas Aquinas, Hegel

3 "Kontradiksi dalam Kesejahteraan Umum", dalam Kompas, 29 November 2011, hal. 6 
dan Tocqueville, bukan pada pemikir klasik moderen seperti Locke, Rousseau dan Kant.

Pokok pikiran liberalisme yang menjadi sasaran gugatan kaum komunitarian dapat diringkaskan sebagai berikut. Dalam liberalisme terdapat distingsi tegas antara konsep keadilan dan pandangan tentang hidup baik, legalitas dan mcralitas. Tugas negara ialah menciptakan dan menjamin sistem hak atas dasar faham HAM, mengkoordinasi ruang-ruang kebebasan individual secara maximal berdasarkan prinsip hukum yang berlaku umum (Immanue! Kant). Pertanyaan seputar hidup baik bukan menjadi kewenangan negara tapi masuk dalam ranah privat, namun konsep hidup baik itu tidak pernah boleh bertentangan dengan prinsip hukum. Dengan demikian hukum membatasi kebebasan pandangan hidup baik.

Komunitarisme mengajukan beberapa catatan kritis atas pandangan kaum liberal. Ada pun beberapa point penting kritikan kaum komunitarian tersebut: ${ }^{4}$

Pertama, kaum komunitarian menolak konsep antropologi liberal yang melihat manusia sebagai „unencumbered self $f^{\star}$ atau manusia tanpa komunitas. Manusia dalam pandangan kaum liberal dimengerti sebagai individu yang terisolir dan melayang-layang di ruang kosong serta ditempatkan dalam ruangruang hak kebebasan. Dalam kenyataanya, demikian kaum komunitarian, manusia selalu hidup dalam komunitas, tradisi dan ikatan sosial. Sebuah sistem sosial yang tidak menggubris aspek-aspek sosial ini dan hanya membatasi diri pada pemahaman tentang manusia sebagai pribadi hukum dalam ruang-ruang kebebasan, menghancurkan substansi sosial hidup manusia dan cenderung menghantar masyarakat kepada bahaya individualisasi, atomisasi dan penghancuran nilai solidaritas.

Kedua, bahaya atomisasi sosial dan melemahnya solidaritas dipertajam lagi dengan dominasi imperatif ekonomi. Rationalitas ekonomi pasar terus mengikis dan memarjinalisasi dimensi etis, kultural dan religius bersama tradisi dan komunitas-komunitasnya (agama misalnya).

4 Bdk. Arno Anzenbacher, Cbristicbe Sozialetbik. Einfübrung und Prinzipien, Paderbom. München. Wien. Zürich: Ferdinand Schôningh, 1997, hal. 117 
Ketiga, solusi apa yang ditawarkan kaum komunitarian untuk mengatasi bahaya individualisasi, ekonomisasi dan desolidarisasi (Entsolidarisierung)? Solusi kaum komunitarian ialah dengan menawarkan dan memperkuat komunitaskominitas, kelompok-kelompok dan tradisi komunitarian di mana manusia dapat mengalami, mempratikkan dan menginternalisasi identitas kultural, etos sosial, solidaritas dan makna bersama. Komunitarisme menawarkan solusi dengan mengikat kembali "unencumbered self“ ke dalam keluarga, sanak saudara, tetangga, komunitas agama, jaringan sosial dan segala macam persekutuan sosial sampai akhimya identitas sosial bangsa yang mampu memberikan makna hidup. Keutarnaan etis untuk melawan egoisme ekonomis hanya mungkin dikembangkan melalui proses integrasi ke dalam komunitas dan tradisi komunitarian. Tanpa sikap-sikap yang dihayati dan ditradisikan secara komunitarian, sebuah masyarakat akan mengalami degradasi menjadi semata onggokan (Haufen-Taylor) pribadi juridis yang tak berdaya di hadapan "despotisme administratif (Bellah), yang kemudian berakhir pada individualisme birokratis (Macintyre) dan kebingungan publik yang tanpa arah (Barber).

Keempat, cita-cita kaum komunitarian berkait erat dengan kritik budaya. Charles Taylor dalam Sources of the Self berpendapat bahwa modernitas dalam wajah liberal telah melupakan akar, substansi dan sumber kehidupannya. ${ }^{5}$ Akar dan sumber mata air kehidupan moderen dan juga sumber bagi subjek bebas atas dasar faham hak-hak asasi manusia bersifat pandangan hidup, religius dan metafisis. Hanya modernitas yang merefleksikan sumber kehidupannya dan membaharui diri lewat proses refleksi tersebut dapat menjadi pengawal dan pembela kebebasan dan martabat manusia. Mengeringnya sumber mata air modernitas tersebut jelas menggoncangkan basis legitimasi bangunan kultural moderen. Karena itu keadilan dan hukum berpijak pada konsep hidup baik dan mengandaikan konsep hidup baik. Tanpa pilihan makna dan nilai hidup baik yang dihayati serta berpijak pada tradisi etis-religius dan ideologis, sistem hukum moderen (hak dan keadilan) akan remuk seketika.

\footnotetext{
${ }^{5}$ Bdk. Chatles Taylor, Quellen des Selbst. Die Entstehung der neuzeitlichen Identität, Frankfurt am Main: Suhrkamp, 1994
} 
Pentingnya konsep hidup baik dalam kehidupan manusia mendorong Taylor untuk mentematisasi konsep hidup baik sebagai persoalan publik dan bukannya persoalan privat seperti pandangan kaum liberal. Hal ini diuraikan Taylor lebih lanjut dalam politik pengakuan.

\section{Relevansi sebuah Perdebatan}

\section{Liberalisme Politik}

Untuk konteks Indonesia yang multikultural, keterbukaan terhadap nilainilai liberal harus diungkapkan dalam kesediaan untuk menerima faham liberal tentang pembedaan antara negara dan masyarakat, politik dan agama. Pilihan makna dan nilai pandangan hidup serta konsep hidup baik dan pemeliharaannya harus berlangsung dalam konteks masyarakat liberal atau bebas. Negara dapat memberikan garansi otonomi hukum dan etis kepada warga negara sebagai pribadi juridis di mana setiap pribadi dapat mendefinisikan dirinya sebagai pribadi etis dan membangun hubungan komunitarian dengan yang lainnya.

Setiap negara moderen yang dibangun atas basis pengakuan akan multikulturalisme harus berani hidup dalam dan menerima dialektika penuh ketegangan antara negara dan agama, keadilan dan konsep tentang hidup baik. Atau dalam bahasa mantan Presiden Mahkamah Konstitusi Jerman, Enst Wolfgang Böckenförde: "Der freibeitliche, sälksilarisierte-Staat lebt von Voraussetzungen, die er selbst nicht garantieren kani"' - 'Negara liberal-sekuler hidup dari syarat-syarat yang tak dapat dijaminnya sendiri:"’

Paradoksi ini, demikian Böckenförde, harus diterima setiap negara liberal yang mau menghargai pluralitas dan menyelamatkan kebebasan individu. Sebuah negara demokratis moderen hanya mungkin eksis secara legitim jika ia mampu menjamin dan melindungi kebebasan setiap warganya. Di satu sisi kebebasan individu merupakan tujuan dan dasar kèberadaan sebuah negara.

Akan tetapi di sisi lain inti dari kebebasan tersebut yakni suara hati tidak pernah boleh dan tidak dapat diatur menurut norma-norma hukum positif. Sebab ketika negara lewat hukum positif masuk ke dalam ranah privat

\footnotetext{
.6. Ernst Wolfgang: Bōckenfōrde, Staat, Gesellschaft, Frebeit. Studien zur Staatstbeorie und zum Vefassungsrecbt, Frankfurt am Main: Suhrkamp, 1976, hal 60
} 
kebebasan suara hati, ia sesungguhnya telah menjadi totaliter. Paradoksi yang dikemukakan Böckenförde di atas merupakan jalan yang telah dan tetap dilewati pemikiran dan praktek politik Eropa moderen. Jalan ini telah menghantar mereka keluar dari konflik berdarah dan perang antara agama dan kelompok etnis yang melanda Exopah pada abad ke-17. Dan hingga kini konsep negara liberal-sekular tetap mampu menjaga perdamaian umum.

Kebebasan manusia terungkap lewat keputusan otonom dan atas pertimbangan suara hati yang tidak pernah boleh serta tidak dapat diintervensi oleh instansi luar. ' Kebebasan hanya dapat meregulasi dirinya dari dalam, dari substansi moral setiap individu dan homogenitas sebuah masyarakat. Bahaya totalitarisme mulai mengintip ketika negara misalnya lewat hukum positif mau mengatur suara hati dan keutamaan pribadi watga negara. Di sini negara berambisi mengatur segala-galanya termasuk cara berpikir dan moralitas warganya yang seharusnya mustahil dapat dilaksanakannya. Ambisi negara ' tersebut menciptakan konflik dan membahayakan perdamaian umum sebab ia menyangkal adanya pluralitas budaya, agama, tingkah laku dan kebebasan berpikir dalam sebuah negara moderen.

Indonesia sebagai bangsa yang mulitikultural harus mampu mènangkal tendensi komunitarisme yang coba mempersoalkan kembali distingsi antara negara dan masyarakat, antara pribadi juridis dan etis serta mau menghidupkan sebuah negara „kebenaran“ (regim agama, ideologi, pandangan hidup).

Tendensi komunitarian yang intoleran ini muncul di Indonesia terutama dalam bentuk fundamentalisme agama. Kaum fundamentalis melakukan teror dan menghalalkan kekerasan untuk membasmi kelompok-kelompok lain. Dengan membajak demokrasi prosedural kelompok "fundamentalis telah berhasil menciptakan dan menggolkan sejumlah produk hukum yang antimultikultural seperti Undang-Undang Pomografi serta ratusan peraturan daerah yang bemuansa Syariah. ${ }^{8}$ Cita-cita untuk membangun sebuah negara

7 Bdk Franz Magnis -Suseno, Etika Poltitik. Prinsip-prinsip Moral Dasar Kenegaraan Moderen, Jakarga: Gramedia Pustaka Utama, 1999; hal. 348

${ }^{8}$ Bdk. Adnan Buyung Nasution, Demokrasi Konstitusional, Jakarta: Penerbit Buku Kompas, 2011, hal. 122 
dengan berbasiskan ideologi atau agama tertentu merupakan sebuah bentuk kemunduran sejarah peradaban umat manusia. Untuk mengatasi hal ini demokrasi prosedural harus dilengkapi dengan substansi demokrasi yang membatasi kesewenangan kekuasaan dan kesewenangan kehendak mayoritas. Substansi demokrasi adalah hak-hak asasi manusia.

\section{Kritik atas Patologi Liberalisme}

Liberalisme politik yang sudah mulai dipraktikkan di Indonesia perlu disempurnakan dengan faham komunitarian. Dialektika antara yang partikular dan universal harus dibangun secara kreatif. Praktik etbos HAM universal misalnya tidak boleh mematikan nilai-nilai komunitarian yang terkandung dalam agama-agama dan budaya-budaya lokal. Sebab, secara konkret individu tak pernah hidup sebagai unencumbered self atau individu tanpa komunitas. Namun imperatif pasar yang cenderung mengkolonisasi semua ranah kchidupan telah "melemankan kepakan sayap-sayap solidaritas sosial dan kultural yang memberi rasa identitas dan kekitaan"."

Tantangan ini tak dapat ditemukan solusinya dalam liberalisme. Filsuf Hannah Arendt menganjurkan agar hak-hak liberal klasik perlu disempurnakan dengan "hak-hak kultural yang melindungi bentuk-bentuk komunitas konkret dan hak-hak partisipasi politis yang dapat membatasi kekuasaan pasar secara demokratis". ${ }^{10}$

Untuk konteks Indonesia yang plural, solusi komunitarian selain dijalankan oleh agama dan kebudayaan, juga diperankan oleh Pancasila. Pancasila adalah loous kontekstualisasi konsep universal hak asasi manusia di Indonesia agar menjadi bagian dari hidup masyarakat. Pancasila juga mencegah bahaya privatisasi konsep hidup baik seperti dipraktikkan dalam masyarakat liberal.

Pancasila tidak menghendaki adanya agama negara di Indonesia. Namun itu tidak berarti, Pancasila sepakat dengan pandangan kaum liberal yang memandang agama sebagai persoalan privat semata. Pancasila menghendaki

9 F. Budi Hardiman, Hak-Hak Asasi Manwsia Polemik dengan Agama dan Kebudayaan, Yogyakarta: Penerbit Kansius, 2011, hal 38

10 Ibid. 39 
agar nilai-nilai agama diterjemahkan menjadi moralitas publik. Di sini konsep ketuhanan dalam Pancasila berperan seperti agama sipil (civic religion) yang berurusan dengan moralitas publik dan tidak mencampuri moralitas serta keyakinan pribadi. Atau seperti dirumuskan Yudi Latif:

...dalam kerangka ketuhanan menurut Pancasila, boleh saja seseorang secara pribadi tidak memeluk agama formal (sebagai agnostik atau bahkan ateis). Akan tetapi, dalam kehidupan publiknya harus tetap menghormati nilai-nilai Ketuhanan-keagamaan seperti dikeehndaki Pancasila berdasarkan hasil kesepakatan konstitusional, sehingga tidak diperkenankan menyebarkan propaganda untuk menolak atau membenci agama. ${ }^{11}$

Mengingat pentingnya peran publik agama, Pancasila membuat koreksi atas tesis "privatisasi" agama kaum liberal dan menganjurkan paradigma diferensiasi dalam relasi antara agama dan negara. Sebab, "ketika agama tersudut dari ruang publik ke ruang privat, yang muncul adalah ekspresi spiritualitas personal yang terputus dari kehidupan publik Sebailiknya, politik sekuler memandang rendah nilai-nilai agama dan mengabaikan signifikansi moral ketuhanan. Akibat yang ditimbulkan oleh situasi saling mengabaikan ini adalah spiritualitas tanpa pertanggungjawraban sosial, dan politik tanpa jiwa."12 Untuk itu fundamentalisme, baik fundamentalisme agama maupun fundamentalisme sekuler harus dihindari. Maraknya korupsi di tengah pesatnya perkembangan agama-agama di Indonesia merupakan bukti kasat mata bahwa agama masih dihayati sebagai ritus kesalehan privat dan belum menjadi kekuatan moral di ruang publik.

Peran publik agama menuntut agama untuk membela sendiri kebebasannya serta kebebasan agama-agama lain. Agama juga dapat mempersoalkan tendensi absolutisme dunia sekuler dan absolutisme kekuasaan negara yang membahayakan kehidupan manusia tanpa harus merebut dan mendominasi seluruh ranah kehidupan manusia. ${ }^{13}$ Di tengah arus modemisasi yang ditandai dengan kolonialisasi sistem teknologi dan birokrasi kekuasaan yang anonim atas

11 Yudi Latif, Negara Paripuma Historisitas, Rasionalitas dan Aksualitas Pancacila, Jakarta: Kompas Gramedia, 2011, hal. 112

12 Ibid, hal. 104

${ }^{13}$ Bdk Ibid, hal. 109 
dunia kehidupan (Lebenswelt), agarna tampil sebagai sumber mata air moralitas dan pemberi rambu-rambu etis.

Ketuhanan dalam kerangka Pancasila mengungkapkan komitmen bangsa Indonesia untuk menata kehidupan politik-publik atas dasar nilai-nilai moral : universal agama-agama serta budi pekerti yang luhur. Krisis moral yang dihadapi masyarakat moderen serta fenomen kebangkitan agama-agama dalam masyarakat sekular membuat paradigma ketuhanan dalamı kerangka Pancasila menjadi penting dan semakin relevan.

Dalam masyarakat Barat sejak tahun 90-an paradigma sekuler yang meminggirkan agama ke ruang privat mulai goyah dan tema agama kembali meramaikan diskursus di ruang publik. ${ }^{14}$ Habermas misalnyanya yang menganggap dirinya "religiős unmusikalisch" (tak berbakat secara religius) menyadari kembali akan pentingnya peran agama di ruang publik dan mengembangkan konsep masyarakat postsekuler. Mengapa masyarakat liberalsekuler kembali kepada agama?

Mungkin salah satu jawaban atas pertanyaan ini adalah rambu-rambu kritis salah seorang teolog Katolik abad ini, Hans Küng, yang dialamatkan kepada masyarakat moderen sekular yang mau mendepak agama ke raung privat irasionalitas: "Kendatipun manusia mewajibkan dirinya untuk taat pada normanorma moral, satu hal tetap tak dapat dilakukan manusia tanpa agama: memberikan pendasaran atas keniscayaan dan universalitas kewajiban-kewajiban moral."15

Pendasaran terakhir tak tergoyahkan tentang keharusan dan universalitas norma-norma moral, demikian Kueng, tak dapat berpijak pada argumentasi filosofis abstrak semata-mata. Filsafat hanya mampu menyentuh intelek manusia. Sementara keharusan nilai-nilai moral harus dapat menggugah ranah perasaan manusia, ruang di mana agama-agama dapat menembusnya dan

\footnotetext{
14 Bdk. Otto Gusti Madung, "Etos Global dan Dialog Peradaban", dalam Kompas 27 Februari 2010

${ }^{15}$ Bdk. Hans Küng, "Leitlinien zum Weiterdenken", dalam: Hans-Martin SchơenherrMann, Miteinder Leben Lemen, Mứncehen: Piper Verlag 2008, hal. 387
} 
bergerak. Karena itu krisis moralitas masyarakat moderen menuntut peran aktif agama-agama dalam ruang publik.

Orientasi makna dan nilai sebuah masyarakat bergantung pada vitalitas tradisi, budaya, agama, model-model etos serta tatanan sosial di mana makna dan nilai tersebut dirawat dan dihayati. Pancasila merupakan suatu model pengawetan dan vitalisasi tradisi tersebut. Orientasi makna ini penting dalam hidup sosial. Sebab, konstitusi dan hukum yang paling rasional sekalipun belum menjadi jaminan dalam berperang melawan masyarakat yang intoleran, akrab dengan kekerasan, korup dan rakus.

Konsep komunitarian berperan sebagai elemen motivasional yang menggerakkan etbos hak-hak asasi manusia. Secara kodrati "rasa kemanusiaan" kita alami pertama-tama dalam solidaritas kelompok seperti agama, suku dan budaya. Manusia universal tak pernah menderita, yang menderita adalah orang Papua, orang Açeh atau warga Ahmadiyah. Pancasila adalah orientasi makna bersama dan sebagai sistem etika bangsa ia memberikan rambu-rambu untuk keluar dari pelbagai krisis etika publik yang tengah melanda bangsa Indonesia.

\section{Pancasila dan Multikulturalisme ${ }^{16}$}

Dengan menjadikan Pancasila sebagai basis ideologi bukan berarti negara Indonesia mengabaikan prinsip netralitas negara. Negara yang netral secara ideologis lebih dari sekedar institusi birokratis. Prinsip netralitas negara moderen sekurang-kurangnya memiliki tiga makna. ${ }^{17}$ Pertama, netralitas akibat atau konsekwensi. Itu berarti penerapan prinsip-prinsip liberal memiliki konsekwensi yang sama untuk semua komunitas dalam sebuah negara. Kedua,

16 Pluralisme dan multikulturalisme sama-sama mengungkapkan kebhinekaan dan perbedaan.Perbedaannya, pluralisme menjelaskan fakta antropologis kebhinekaan dan keberbedaan tersebut tanpa membuat penilaian. Sedangkan multikulturalisme berkaitan dengan sikap etis yang berintikan penghargaan terhadap kebudayaan dan pandangan hidup yang berbeda-beda sambil terus mendorong dialog dan kerja sama yang produktif antara elemenelemen yang berbeda dan beraneka tersebut (Bdk. Willy Gaut, "Mengakui Kemajemukan, Merayakan Perbedaan", dalam Seri Buku Vox 55/02-04/2011, Ledalero 2011, hal. 119)

17 Bdk. Rainer Forst, Kommunitarismus und Liberalismus - Stationen einer Debatte, dalam: Axel Honneth (Ed.): Komunitarismus. Eine Debatte über die moraliscben Grundlagen moderner Gesellscbaften, Campus Verlag: Frankfurt am Main 1993, hal. 192 
netralitas tujuan. Negara liberal tak pernah boleh mengutamakan konsep hidup baik tertentu berhadapan dengan pandangan atau ideologi lainnya. Persis itu yang terjadi jika negara didirikan atas dasar ideologi agama tertentu. Ketiga, netralitas legitimasi atau pembenaran. Basis legitimasi prinsip-prinsip keadilan tak boleh berpijak pada nilai-nilai etis komunal tertentu, namun bertumpuh pada konsep moral universal dan tak berpihak.

Asas netralitas dari liberalisme ini merupakan prestasi peradaban umat manusia dan telah berhasil mengatasi konflik antara agama dan ideologi yang melanda masyarakat Eropa. Konsep ini harus diterapkan di Indonesia yang multikultural agar perbedaan dan kebhinekaan tidak menjadi sumber konflik tapi kekayaan bangsa.

Negara yang menganut prinsip netralitas tetap dapat memainkan peran secara politis agar diskursus seputar ideologi, pandangan hidup dan konsep hidup baik merupakan objek tematisasi di ruang publik. Dalam bidang pendidikan dan ilmu pengetahuan negara dapat mengatur sekian agar dominasi pengetahuan instrumental yang menekan dapat dibatasi demi kepentingan kompetensi pandangan hidup.

Negara liberal dapat mengembangkan pengetahuan tentang pelbagai tradisi filsafat dan agama serta kesadaran akan pluralitas persoalan ideologis di sekolahsekolah dan universitas dan bukan sebaliknya mendepak persoalan ideologis dan agama ke ruang privat irasionalitas. Negara yang dibangun atas semangat multikulturalisme sadar akan pentingnya komunitas-komunitas yang menawarkan dan menjaga orientasi etis-religius serta terlibat dalam kegiatankegiatan solidaritas-karitatif. Institusi-institusi komunitarian seperti agama, kelompok adat, dan lain-lain dapat menawarkan diri sebagai forum diskursus tentang pandangan hidup. Dengan memberi penekanan pada politik kebudayaan model ini negara dapat menanggapi secara produktif idealisme komunitarian tanpa harus berhenti menjadi negara moderen.

Dalam seluruh proses diskursus publik seputar pandangan hidup Pancasila dapat berperan sebagai substansi normatif yang memberikan panduan agar nilainilai kehidupan bersama seperti toleransi, kebebasan, persamaan, solidaritas, ketaatan terhadap hukum dan pantang akan kekerasan tatap dijaga dan dipegang 
teguh. Dengan demikian Pancasila dapat menjadi basis pengakuan dalam masyarakat multikultural agar setiap pribadi, kelompok, pandangan hidup dan agama dapat mewujudkan dirinya secara otentis tanpa harus membahayakan yang lain.

\section{Penutup}

Indonesia adalah sebuah masyarakat yang multikultural. Pengakuan merupakan salah satu sikap etis yang penting dalam menghadapi kebhinekaan dan keberbedaan tersebut. Pengakuan memungkinkan yang lain mengekspresikan dan mengembangkan dirinya secara otentis. Namun pengakuan akan keberbedaan dan keanekaragaman semata tanpa adanya basis substansi moral yang sama belum cukup menjadi landasan kokoh sebuah kehidupan bersama.

Dalam sebuah masyarakat multikultural nilai-nilai komunai perlu ditransformasi menjadi nilai-nilai etika publik agar dapat diterima oleh semua. Pancasila tidak lain dari etika publik tersebut yang telah mengatasi sekat-sekat komunal. Pancasila juga memberikan rambu-rambu normatif apakah nilai-nilai komunal tertentu layak diterima sebagai norma bersama di ruang publik. Dalam dialog terus-menerus dengan nilai-nilai komunal dan global Pancasila menampakkan dinamikanya sebagai identitas bangsa. Sebuah identitas yang selalu terbuka untuk ditafsir kembali.

\section{DAFTAR PUSTAKA}

Buyung Nasution, Adnan. 2011. Demokrasi Konstitusional. Jakarta: Penerbit Buku Kompas.

Anzenbacher, Amo. 1997. Christliche Sozialethik Einfübrung und Prinzipien. Paderbom. Mũnchen. Wien. Zürrich: Ferdinand Schőningh.

Böckenfốrde, Emst Wolfgang. 1976. Staat, Gesellschaft, Frebeit. Studien zur Staatstbeorie und zum Verfassungsrecht. Frankfurt am Main: Suhrkamp.

Budi Hardiman, F. 2011. Hak-Hak Asasi Manusia. Polemik dengan Agama dan Kebudayaan. Yogyakarta: Penerbit Kansius. 
Forst, Rainer. 1993. Kommunitarismus und Liberalismus - Stationen einer Debatte, dalam: Axel Honneth (Ed.): Komunitarismus. Eine Debatte über die moralischen Grundlagen moderner Gesellschaften. Frankfurt am Main: Campus Verlag

Gaut, Willy. 2011. "Mengakui Kemajemukan, Merayakan Perbedaan", dalam Seri Buku Vox 55/02-04/2011, Ledalero

Gusti Madung, Otto. 2010. "Etos Global dan Dialog Peradaban", dalam Kompas 27 Februari

Küng, Hans. 2008. "Leitlinien zum Weiterdenken", dalam: Hans-Martin Schoenherr-Mann. Miteinder Leben Lemen. Mũncehen: Piper Verlag

Latif, Yudi. 2011. Negara Paripuma. Historisitas, Rasionalitas dan Aktualitas Pancasila. Jakarta: Kompas Gramedia

Magnis -Suseno, Franz. 1999. Etika Politik. Prinsip-prinsip Moral Dasar Kenegaraan Moderen. Jakarga: Gramedia Pustaka Utama.

Taylor, Charles. 1994. Quellen des Selbst. Die Entstehung der neuzeitlichen Identität. Frankfurt am Main: Suhrkamp 